\title{
A TEORIA DA PERDA DE UMA CHANCE: CRITÉRIOS DE APLICAÇÃO E BREVE ANÁLISE ACERCA DA RECENTE ADMISSÃO DOUTRINÁRIA E JURISPRUDENCIAL NO ORDENAMENTO JURIIDICO BRASILEIRO
}

\author{
THE THEORY OF LOSS OF A CHANCE: \\ APPLICATION CRITERIA AND BRIEF \\ ANALYSIS ABOUT THE RECENT \\ ADMISSION AND DOCTRINE AND \\ JURISPRUDENCE LAW IN BRAZILIAN
}

\section{Taynara Larissa da Silva ${ }^{1}$}

\section{Feliciano Alcides Dias ${ }^{2}$}

\begin{abstract}
Resumo: Este artigo trata da teoria da responsabilidade civil pela perda de uma chance, com o principal objetivo em analisar os critérios de sua aplicação no ordenamento jurídico brasileiro, em particular, a verificação sobre a atual recepção da teoria de perda de uma chance no direito brasileiro; a identificação da forma de determinação do quantum indenizatório, caso seja aplicada a teoria. A perda de uma chance é a frustração de uma oportunidade de obter um benefício, esperada pela vítima, caso não houvesse o corte abrupto em decorrência do ato do lesante, que

gera o dever de indenizar. Estruturado por meio do método indutivo, com pesquisas em fontes normativas, doutrinárias e análise de casos. Demonstra-se com este estudo, que a teoria da perda de uma chance é aceita pela maioria da doutrina e também pela jurisprudência pátria. Para a aplicação da teoria, a chance perdida deve ser séria e real e a indenização proporcional à possibilidade de obter sucesso na chance perdida.

Palavras-chave: Responsabilidade civil. Perda de uma chance. Chance perdida. Probabilidade.
\end{abstract}

1 Pós-graduada em Direito Público pela Universidade Regional de Blumenau (FURB) e Escola Superior da Magistratura do Estado de Santa Catarina (Esmesc). Pós-graduanda em Direito Aplicado pela FURB e Esmesc. Assessora Jurídica do Tribunal de Justiça de Santa Catarina (TJSC). E-mail: taynaralsilva@gmail.com

2 Doutorando em Direito Público pelo Programa de Pós-Graduação em Direito da Universidade do Vale dos Sinos (Unisinos), Mestre em Ciências Jurídicas pela Universidade do Vale do Itajaí (Univali); Especialista em Direito Civil pela Univali; Professor e Coordenador da Esmesc na Extensão de Blumenau; Professor, Pesquisador e Extensionista da FURB no Curso de Direito. E-mail: feliciano@furb.br 
Abstract: This article deals with the theory of liability for loss of a chance, with the main objective an analysis of the application criteria and the applicability of the theory of loss of a chance in the Brazilian legal system, in particular to check on the current reception theory loss of a chance in Brazilian law; the application of the analysis of the theory of loss of chance; identify the way of determining the quantum indemnity, if the theory is applied. Loss of a chance is the frustration of an opportunity to obtain a benefit, expected by the victim if there is not a result of the sharp cut-off act of agent, which generates a duty to indemnify. Structured through the inductive method, with research in normative sources, doctrine and case studies. Demonstrates that the theory of loss of chance is accepted by the majority of doctrine and also the jurisprudence homeland. For the application of theory, the lost chance to be serious and real, and that the compensation is proportional to the prospects for success in the lost chance.

Keywords: Liability. Loss of a chance. Chance lost. Probability.

\section{INTRODUÇÃO}

Uma nova forma de reparação civil de ato ilícito chama a atenção pelo recente destaque que vem recebendo, tanto da doutrina quanto da jurisprudência. É a chamada responsabilidade civil pela perda de uma chance.

Diante do significado da palavra chance, é possível imaginar situações em que se propicia a uma pessoa a oportunidade de vir a obter no futuro algo benéfico. Quando se fala em perda de chances nos estudos sobre responsabilidade civil, é porque esse processo foi interrompido por certo fato antijurídico e, por isso, a oportunidade restou perdida.

Assim, a chance perdida pode ser representada tanto pela frustração da oportunidade de obter uma vantagem, como pela frustração da oportunidade de evitar um dano que, em decorrência disso, depois se verificou.

Dessa forma, este trabalho tem como objetivo uma análise sobre os parâmetros de aplicabilidade atual da teoria da perda de uma chance no sistema jurídico brasileiro.

A metodologia empregada corresponde à adoção do método indutivo, com pesquisas em fontes normativas, doutrinárias 
e análise de casos. Este método será utilizado para delinear o tema, devido à ampla abrangência do assunto, visando um trabalho objetivo e de fácil compreensão.

\section{A TEORIA DA PERDA DE UMA CHANCE}

O conceito de dano pela perda de uma chance foi utilizado pela primeira vez já no século XIX na França. Precisamente em 17 de julho de 1889, a Corte de Cassação francesa conferiu indenização a um demandante pela atuação culposa de um oficial ministerial que extinguiu todas as possibilidades de a demanda lograr êxito, mediante o seu normal procedimento (SILVA, 2013, p. 11).

Após a primeira utilização da teoria da perda de uma chance, o campo de sua aplicação foi ampliado pelos juízes franceses, fazendo a teoria alcançar diversas noções de responsabilidade civil. Nos dias atuais, a teoria da perda de uma chance é utilizada nos danos oriundos do inadimplemento contratual, naqueles gerados pelos ilícitos absolutos e nas hipóteses regidas pela responsabilidade subjetiva e objetiva (SILVA, 2013, p. 11-12).

\subsection{Conceito}

Há um sem-número de situações que ocorrem na vida cotidiana em que alguém se vê privado da oportunidade de obter uma determinada vantagem ou de evitar um prejuízo, tendo em vista o ato ofensivo de uma pessoa. Os exemplos são os mais variados, dentre os mais conhecidos encontra-se o clássico do advogado que perde o prazo para interpor recurso de apelação contra sentença contrária aos interesses de seu cliente.

Desse modo, ninguém poderia assegurar, com absoluta certeza que, caso interposto, o recurso seria provido. Entretanto, ao analisar o caso concreto, é possível considerar quais eram as 
chances reais de o recurso ser provido, bem como se a hipótese consistia em mera possibilidade ou em efetiva e séria probabilidade (SAVI, 2006, p. 1).

O dano decorrente da perda da oportunidade de obter uma vantagem ou de evitar um prejuízo foi, por muito tempo, ignorado pelo Direito, haja vista a impossibilidade de se afirmar, com certeza, que sem o ato do ofensor, a vantagem esperada seria obtida. Portanto, ignorava-se a existência de um dano diverso da perda da vantagem esperada, ou seja, o dano da perda da oportunidade de obter aquela vantagem.

$\mathrm{Na}$ atualidade, diante da evolução das estatísticas e das probabilidades,

[...] é possível visualizar um dano independente do resultado final. Se, por um lado, a indenização do dano consistente na vitória perdida (na causa judicial, por exemplo) é inadmissível, ante a incerteza que lhe é inerente, por outro lado, não há como negar a existência de uma possibilidade de vitória, antes da ocorrência do fato danoso. Em relação à exclusão da possibilidade de vitória poderá, frise-se, dependendo do caso concreto, existir um dano jurídico certo e passível de indenização. (SAVI, 2006, p. 3).

No tocante ao progresso nos estudos da probabilidade, no sistema jurídico, a possibilidade de aplicar a teoria da perda de uma chance "[...] foi terreno fértil para o advento de um instrumento dogmático utilíssimo, capaz de criar uma nova categoria de dano indenizável: as chances perdidas." (SILVA, 2013, p. 10).

Dessa forma, antes de conceituar a teoria da perda de uma chance, faz-se necessário, conceituar-se o termo chance. Maurizio Bocchiola (1976 apud Sérgio Savi, 2006, p. 13) afirma que: "O termo chance significa, em sentido jurídico, a probabilidade de obter um lucro ou de evitar uma perda."

Sobre o conceito de chance, Rafael Peteffi da Silva (2013, 
p. 13-14) sustenta que:

A chance representa uma expectativa necessariamente hipotética, materializada naquilo que se pode chamar de ganho final ou dano final, conforme o processo aleatório. Entretanto, quando esse processo aleatório é paralisado por um ato imputável, a vítima experimentará a perda de uma probabilidade de um evento favorável. Esta probabilidade pode ser estatisticamente calculada, a ponto de lhe ser conferido um caráter de certeza.

Diante do significado da palavra chance, é possível imaginar situações em que se propicia a uma pessoa a oportunidade de vir a obter no futuro algo benéfico. Quando se fala em perda de chances, nos estudos sobre responsabilidade civil, é porque esse processo foi interrompido por certo fato antijurídico e, por isso, a oportunidade restou perdida. Assim, a chance perdida pode ser representada tanto pela frustração da oportunidade de obter uma vantagem, como na frustração da oportunidade de evitar um dano, que por isso depois se verificou. (NORONHA, 2007, p. 669-670).

Acerca da matéria, Judith Martins-Costa (2003, p. 360) aduz que, "[...] na responsabilidade pela perda de uma chance, o que é indenizado é justamente a chance de não alcançar determinado resultado, ou de auferir certo benefício, chance que foi perdida pela vítima em razão de ato culposo do lesante."

Grácia Cristina Moreira do Rosário (2009 apud Fabiano Mello, 2011, p. 6), traz a seguinte conceituação para a perda de uma chance:

A perda de uma oportunidade ou chance constitui zona limítrofe entre o certo e o incerto, o hipotético e o seguro; tratando-se de uma situação na qual se mede o comportamento antijurídico que interfere no curso normal dos acontecimentos de tal forma que já não se poderá saber se $o$ afetado por si mesmo obteria ou não obteria os ganhos, ou se evitaria ou não certa vantagem, mas um fato de terceiro 
o impede de ter a oportunidade de participar na definição dessas probabilidades.

Fernando Noronha (2007, p. 671), ainda, lembra que: “As vantagens e os prejuízos presentes aqui em questão podem ser patrimoniais ou extrapatrimoniais $[\ldots]$ "..

Importante mencionar que quando aplicada à atividade médica, a teoria ficou conhecida como teoria da perda de uma chance de cura ou de sobrevivência, em que o elemento que determina a indenização é a perda de uma chance de resultado favorável no tratamento. $\mathrm{O}$ que se perde é a chance de cura e não a continuidade da vida. Assim, a perda da chance reside em não se dar ao paciente todas as chances de cura ou de sobrevivência (CAVALIERI FILHO, 2012, p. 86).

Desse modo, verifica-se que a teoria da responsabilidade civil pela perda de uma chance abrange os casos em que, devido à conduta do agente, a vítima perde a oportunidade de auferir uma vantagem.

\subsection{Critérios de aplicação da teoria da perda de uma chance}

Para existir a possibilidade de aplicação da teoria da perda de uma chance em um caso concreto, é necessária a observância tanto dos requisitos gerais da responsabilidade civil [teoria geral da responsabilidade civil - conduta humana [ou culpa), dano e nexo causalidade], quanto dos específicos da perda de uma chance.

\subsubsection{Requisitos específicos da perda de uma chance}

A doutrina pátria elege alguns critérios gerais para aplicação da teoria da perda de uma chance. São estes critérios que caracterizam a teoria da perda de uma chance e que diferem esta espécie das demais hipóteses de responsabilidade civil. 


\subsubsection{Chances sérias e reais}

Não é qualquer oportunidade perdida que pode gerar a responsabilidade civil pela perda de uma chance. Como será verificado, para que a vítima tenha direito de indenização é necessário que a chance perdida de obter alguma vantagem seja séria e real.

O limite da teoria da perda de uma chance se encontra no caráter de certeza que deve apresentar o dano reparável. Desse modo, para que uma demanda com base na teoria da perda de uma chance seja procedente, o autor deverá demonstrar muito mais do que uma simples esperança subjetiva (SILVA, 2013, p. 138).

Todavia, seguindo o entendimento doutrinário acerca da matéria, Sergio Cavalieri Filho $(2012$, p. 81) afirma que: “É preciso, portanto que se trate de uma chance séria e real, que proporcione ao lesado efetivas condições pessoais de concorrer à situação futura esperada. Aqui, também, tem plena aplicação o princípio da razoabilidade."

No mesmo sentido, no caso concreto é importante averiguar se a chance era séria e real, pois se for, haverá obrigação de reparar o dano. Contudo, se a chance for meramente hipotética não haverá obrigação de indenizar (NORONHA, 2007, p. 679). Assim, para compreender se a chance perdida era séria e real, deve-se recorrer às regras do art. 375 do Código de Processo Civil, de $2015^{3}$, ou seja, as regras de experiência comum subministradas pela observação do que ordinariamente acontece.

Nesse contexto, analisa Sílvio de Salvo Venosa (2012, p. 308) que:

[...] a doutrina aconselha efetuar um balanço das perspectivas contra e a favor da situação do ofendido. Da con-

3 De acordo com o novo Código de Processo Civil (BRASIL, Lei n 13.105, 2015, art. 375): "Art. 375. O juiz aplicará as regras de experiência comum subministradas pela observação do que ordinariamente acontece e, ainda, as regras de experiência técnica, ressalvado, quanto a estas, o exame pericial." 
clusão, resultará a proporção do ressarcimento. Trata-se então do prognóstico que se colocará na decisão. Na mesma senda do que temos afirmado, não se deve admitir a concessão de indenizações por prejuízos hipotéticos, vagos ou muito gerais.

Miguel Kfouri Neto (2003, p. 66) argumenta que: “A chance perdida deve ser 'séria', ou 'real e séria'. É necessário demonstrar a realidade do prejuízo final, que não pode ser evitado - prejuízo cuja quantificação dependerá do grau de probabilidade de que a chance perdida se realizaria."

Com efeito, releva notar que a ocorrência da "perda de uma chance repousa sobre uma possibilidade e uma certeza: é verossímil que a chance poderia se concretizar; é certo que a vantagem esperada está perdida - e disso resulta um dano indenizável." (MAZEAUD; MAZEAUD apud KFOURI NETO, 2002, p. 110-111). Desse modo, há incerteza no prejuízo e certeza na probabilidade (KFOURI NETO, 2003, p. 66).

Importante ressaltar que, já na década de 60, fixou-se requisito imprescindível para a adoção da teoria da perda de uma chance, qual seja, o de que simples esperanças aleatórias não podem ser passíveis de indenização (CUPIS, 1966 apud SAVI, 2006, p. 12).

Ao analisar a questão da perda de uma chance na responsabilidade civil do advogado, pondera-se a questão da necessidade da chance ser séria e real, ainda que indiretamente:

Seria necessário, pois, reexaminar, detida e minuciosamente, a questão que seria posta a julgamento para verificar à luz da lei, da doutrina e da jurisprudência, se era provável o êxito da pretensão do cliente. É claro que toda vez que o advogado deixa de recorrer o cliente perde a chance de ver a questão reexaminada pela instância superior. Contudo, nas situações em que, pela matéria discutida, não havia probabilidade de sucesso, não se pode cogitar de dano patrimonial causado pelo advogado, porque o prejuízo material 
sofrido pelo cliente não terá decorrido da falta do recurso, pois este, sem chances de êxito, nenhuma alteração para melhor ensejaria em favor do cliente. (DIAS, 1999, p. 66).

Sobre o clássico exemplo do advogado que perde o prazo para recorrer, Judith Martins-Costa (2003, p. 361) assevera que após a perda do prazo que ocorreu pela negligência do advogado, extingue-se qualquer chance de a ação vir a ser julgada procedente. Assim, não se trata de mera e subjetiva esperança de vencer a causa, muito menos se indeniza o fato de o cliente ter perdido a causa. A chance de o processo ser apreciado por uma instância superior é o que se indeniza. Portanto, as chances eram sérias e reais.

Segundo Sílvio de Salvo Venosa (2012, p. 308):

Se a possibilidade frustrada é vaga ou meramente hipotética, a conclusão será pela inexistência de perda de oportunidade. A "chance" deve ser devidamente avaliada quando existe certo grau de probabilidade, um prognóstico de certeza, segundo avaliamos. [...] O julgador deverá estabelecer se a probabilidade perdida constituiu uma probabilidade concreta, mas essa apreciação não se funda no ganho ou na perda porque a frustração é aspecto próprio e caracterizador da "chance".

Por derradeiro, a teoria da perda de uma chance não merece aplicação nos casos em que a chance da vítima auferir uma vantagem é meramente hipotética, mas sim, deve haver uma probabilidade razoável de que o fato poderia acontecer caso não houvesse interferência do agente.

\subsubsection{Chances sérias e reais no direito comparado}

A doutrina e jurisprudência de alguns países trazem peculiaridades acerca das chances sérias e reais.

Nos Estados Unidos, a preocupação da doutrina e da jurisprudência com a seriedade das chances é tão grande que a 
aplicação da teoria praticamente se restringe aos casos da seara médica, por falta de estatísticas em outras áreas. Na França, por sua vez, apesar da doutrina encontrar as mesmas dificuldades, a aplicação em outros tipos de casos, como empresariais, judiciais e de jogos de azar é mais comum (SILVA, 2013, p. 139-140).

Certa vez, a Corte de Cassação francesa não conferiu indenização para um cliente de uma corretora de valores que geriu de modo fraudulento e incompetente a sua carteira de ações. $\mathrm{O}$ motivo para a Corte de Cassação ter negado a concessão de indenização foi a imprevisibilidade do mercado de ações, mesmo que a carteira de ações fosse administrada por profissional competente. Destarte, a Corte de Cassação francesa reputou que a chance perdida era hipotética demais para ser indenizada (SILVA, 2013, p. 140).

O sistema norte-americano, principalmente, nos casos de responsabilidade civil pela perda de uma chance na área médica, adota o padrão likely than not (mais provável que não). Segundo este padrão de causalidade, se um procedimento médico retirou $51 \%$ das chances de um paciente sobreviver, estaria identificada a existência do nexo de causalidade entre a ação do agente e o nexo causal sofrido pela vítima, tornando inaplicável a teoria da perda de uma chance. Dessa forma, somente pode ser aplicada esta teoria em casos em que o ato do agente retire menos de $50 \%$ das chances da vítima auferir a vantagem esperada (SILVA, 2013, p. 141).

A Corte de Cassação italiana adota caminho oposto. De acordo com ela, para a aplicação da teoria da perda de uma chance é necessário a existência de pelo menos $50 \%$ de chances da vítima alcançar seu desiderato (SAVI, 2006, p. 31).

Rafael Peteffi da Silva (2013, p. 141-142) entende que a linha de raciocínio italiana é isolada, pois negaria indenização em casos de razoáveis probabilidades de alcançar os objetivos, 
por exemplo, $20 \%, 30 \%$ ou $40 \%$ de chances.

Se a tendência encontrada no direito italiano fosse apoiada, casos que tratam da perda da chance de obter aprovação em determinado concurso ou licitação pública, comuns nos ordenamentos francês e norte-americano, somente poderiam ser admitidos se restassem apenas dois concorrentes, pois somente desta maneira a vítima poderia obter mais de 50\% de chances de lograr êxito no certame público. Caso a última fase de um concurso público contasse com quatro candidatos, aquele que fora eliminado injustificadamente nunca poderia ajuizar uma ação de indenização, pois contaria, dependendo do caso concreto, com algo em torno de $25 \%$ de chances de obter sucesso. (SILVA, 2013, p. 142).

Assim, apesar de não existir unanimidade no direito comparado, em relação ao percentual mínimo de chances da vítima obter sucesso no evento aleatório, para a aplicação da teoria da responsabilidade civil pela perda de uma chance, existe consenso de que as chances devem ser, no mínimo, sérias e reais.

\subsubsection{Quantificação das chances perdidas e do quantum indenizatório}

Uma vez determinado o dever de reparar pela perda de uma chance, surge o problema da quantificação da indenização, onde paira inicialmente a dúvida em relação a totalidade ou parcialidade da compensação.

Importante recordar que a responsabilidade civil pela perda de uma chance, apenas é utilizada quando a vítima está impossibilitada de provar o nexo causal entre a conduta do agente e a perda definitiva da vantagem esperada. Pode-se citar como exemplo, o caso do empresário que não logra provar que seu negócio não se realizou pela falha de seu contador, assim como o cliente não consegue provar o nexo causal entre a ação ou omissão do seu advogado e a improcedência da demanda. Portanto, resta para a vítima, a reparação pela perda de uma chance, já que poderá provar o nexo causal entre a conduta do 
agente e as chances perdidas (SILVA, 2013, p. 142-143).

Pode-se dizer, portanto, que a regra fundamental a ser obedecida nos casos em que se pretende aplicar a teoria da responsabilidade civil pela perda de uma chance é que a reparação da chance perdida, sempre deverá ser inferior ao valor da vantagem esperada e, definitivamente, perdida pela vítima. Até mesmo nas espécies de dano moral, esta regra deve ser obedecida.

A aludida regra fundamental foi, de forma sistemática, respaldada pela jurisprudência francesa. Paul-Julien Doll aplaudiu a decisão da Corte de Cassação que cassou um acórdão da Corte de Apelação de Rennes, o qual havia ordenado a integral reparação do dano representado pela morte do paciente, mesmo após constatar que se tratava de um caso de perda de chances, tendo em vista a ausência de nexo causal entre a conduta do réu e a morte do paciente. (SILVA, 2013, p. 143).

Tal regra foi respaldada pela jurisprudência francesa, conforme se verifica do trecho de uma decisão da Corte de Cassação datada de 9 de abril de 2002, extraída da obra de Rafael Peteffi da Silva (2009, p. 143): "a reparação da perda de uma chance dever ser mensurada de acordo com a chance perdida e não pode ser igualada à vantagem em que teria resultado esta chance, caso ela tivesse se realizado."

Em razão da impossibilidade de reparar o dano final que doutrinadores e magistrados afirmam, que a reparação pela perda de uma chance não deve ser entendida como uma reparação integral do prejuízo. Destarte, já se afirmou que isso não quer dizer que o dano pela perda de uma chance não esteja sujeito aos princípios da reparação integral, mas sim, que a indenização concedida sempre repara de forma total as chances perdidas. A perda de uma chance é um dano específico e independente em relação ao dano final, que era a vantagem esperada e que foi definitivamente perdida.

É evidente que a afirmação acima transcrita depende de 
um prévio juízo de valor sobre a natureza jurídica da responsabilidade pela perda de uma chance. Entrementes, os que comungam com a visão da aplicação da teoria da causalidade parcial poderão dela discordar, por entender que as chances perdidas seriam fruto da utilização de uma causalidade parcial, visto que não possuem qualquer autonomia em relação ao dano final. Porém, aqueles que acreditam que a responsabilidade pela perda de uma chance, ou pelo menos algumas aplicações desta teoria, esteja alicerçada em um conceito específico de dano, terão de admitir que a reparação observada em casos de perda de uma chance deve ser conceituada como integral. (SILVA, 2013, p. 144).

Rafael Peteffi da Silva (2013, p. 144) afirma que: "Mesmo que se concorde com a corrente doutrinária que defende a independência das chances perdidas em relação ao dano final, é inegável que este será o grande referencial para a quantificação das chances perdidas."

Ademais, para explicar a referida aplicação, utiliza-se do seguinte exemplo:

[...] aquele proprietário de um cavalo de corrida que esperava ganhar a importância de $\mathrm{R} \$ 20.000,00$ (vantagem esperada), proveniente do primeiro prêmio da corrida que seu cavalo participaria não fosse a falha do advogado, o qual efetuou a inscrição do animal de forma equivocada. Se as bolsas de apostas mostravam que o aludido cavalo possuía vinte por cento $(20 \%)$ de chances de ganhar o primeiro prêmio da corrida, a reparação pelas chances perdidas seria de $\mathrm{R} \$ 4.000,00$. (SILVA, 2013, p. 144).

Jean-Pierre Couturier (1991 apud SILVA, 2013, p. 144), ao utilizar técnicas matemáticas, demonstra a forma de quantificação na teoria da perda de uma chance ao afirmar que, "[...] a 'função chance perdida' é a derivada da 'função vantagem esperada, (dano final) [...]" e varia conforme esta, mesmo mantendo a sua autonomia. 
A metodologia utilizada pela jurisprudência norte-americana guarda as mesmas linhas seguidas pelos juristas franceses. Destarte, em Falcon v. Memorial Hospital, a Suprema Corte de Michigan julgou o caso de uma gestante que faleceu logo após o parto, devido a uma embolia. Os peritos admitiriam que a morte era imprevisível e o médico não poderia ser responsabilizado. Entretanto, trinta e sete e meio por cento $(37,5 \%)$ das pessoas que sofrem o mesmo problema que a Sra. Falcon sobrevivem, desde que recebam o correto tratamento médico. No caso em tela, foi constatado que a falta de uma terapêutica correta por parte do médico retirou as chances de vida da Sra. Falcon. Deste modo, o dano concedido representou trinta e sete e meio por cento $(37,5 \%)$ do valor que seria concedido se o médico fosse considerado responsável pela morte da vítima. (SILVA, 2013, p. 144-145).

Kevin J. Willging (1993 apud SILVA, 2013, p. 145), ao comentar o caso, afirma que a quantificação do dano deve refletir a porcentagem de chances perdidas.

Nesse sentido, o dano pela perda de uma chance será reparado quando há possibilidade de "[...] calcular o grau de probabilidade, que havia, de ser alcançada a vantagem que era esperada, ou inversamente, o grau de probabilidade de o prejuízo ser evitado. $\mathrm{O}$ grau de probabilidade é que determinará o valor da reparação." (NORONHA, 2007, p. 671).

Corrobora na mesma direção Miguel Kfouri Neto (2002, p. 111) ao afirmar que, “[...] é necessário demonstrar a realidade do prejuízo final, que não pode ser evitado - prejuízo cuja quantificação dependerá do grau de probabilidade de que a chance perdida se realizaria."

O montante da indenização deverá estar vinculado à avaliação do dano consecutivo à perda. Se, por exemplo, a indenização integral atingiria cem por cento, mas a vítima teve perdida uma chance, em duas razoavelmente possíveis, a indenização seria de cinquenta por cento. (KFOURI NETO, 2002, p. 111). 
No direito italiano, apesar de que, como já visto, haver diferenças em razão do percentual mínimo necessário para a concessão da indenização, a forma quantificação da reparação segue a mesma esteira dos outros países.

Ao se quantificar a reparação do dano pela perda de uma chance na península Apenina, o juiz deverá partir do dano final e fazer incidir sobre este o percentual de probabilidade de obtenção da vantagem esperada. A Corte di Cassazione utiliza, nesses casos, a seguinte fórmula: "VIP $=$ VRF x Y, onde: VIP $=$ valor da indenização da chance perdida; $\mathrm{VRF}=$ valor do resultado final; $Y$ = percentual de probabilidade de obtenção do resultado final." (SAVI, 2006, p. 32).

Na maioria dos casos de perda de uma chance até aqui apresentados, necessitava-se apenas analisar somente um evento aleatório para o cálculo de probabilidade. Entretanto, em algumas hipóteses, o cálculo das chances perdidas deverá levar em conta a participação de dois ou mais eventos aleatórios. Todavia, apesar de o aparecimento dessas hipóteses não ser tão raro, os tribunais norte-americanos dificilmente explicam, de maneira satisfatória, como efetuaram a interrelação das múltiplas variáveis que interferem na quantificação das chances perdidas. (KING JR., 1998 apud SILVA, 2013, p. 146).

Quando dois fatores aleatórios são combinados para a constituição de um evento, a probabilidade de tal evento acontecer diminui exponencialmente. A regra que determina a junção de dois ou mais fatores aleatórios pode ser descrita assim: "a probabilidade de dois eventos ocorrerem é igual à probabilidade de o primeiro evento ocorrer, multiplicada pela probabilidade de ocorrência do segundo evento, depois de se saber que o primeiro evento de fato ocorreu." (KING JR., 1998 apud SILVA, 2013, p. 146).

Como bom exemplo, cita-se: 
[...] o caso do médico que na primeira consulta falha em indicar a realização de um exame complementar cuja necessidade era facilmente demonstrada pelo quadro clínico apresentado pela paciente. Dezoito meses depois, descobre-se que a vítima está com câncer terminal. Se o médico tivesse diagnosticado a doença mediante exame complementar à época da primeira consulta, a paciente teria cinquenta e cinco por cento de chances de ter uma sobrevida normal. Porém devido ao local do tumor cancerígeno, a chance do aludido exame complementar diagnosticar a doença não era de cem por cento, mas de apenas oitenta e cinco por cento. Dessa forma, há que se considerar os dois fatores aleatórios em jogo, pois não era absolutamente certo que a paciente viveria após o diagnóstico tempestivo, bem como não era absolutamente certo que o exame complementar levaria a um diagnóstico correto. Assim, a chance de sobrevida perdida foi de $46,75 \%$, eis que 0,85 multiplicado por 0,55 é igual a 0,4675 . (KING JR., 1998 apud SILVA, 2013, p. 147).

Este tipo de cálculo, em que existe mais de um evento aleatório para determinar o percentual da chance perdida foi denominado de princípio da conjuction.

Assim, pelo menos em relação à quantificação da reparação do dano causado pela perda de uma chance existe unanimidade na doutrina comparada, ao afirmar que o valor da reparação será proporcional ao percentual de chances ao grau de probabilidade do lucro ser obtido, caso a chance não fosse perdida.

\subsection{A APLICAÇÃO DA TEORIA DA PERDA DE UMA CHANCE NO ORDENAMENTO JURÍDICO BRASILEIRO}

Uma das primeiras dificuldades para a aplicação da teoria da perda de uma chance no direito brasileiro é a ausência de fundamento legal para sua efetivação. "Para melhor aplicação da Teoria da Perda de uma Chance, é necessário encará-la como um novo instituto no ordenamento jurídico brasileiro, 
que, embora não codificado, possui forte presença na doutrina." (MELLO, 2011, p. 8).

Como visto, um dos requisitos para a aplicação da teoria da perda de uma chance é de que a chance perdida deve ser séria e real. Rafael Peteffi da Silva (2013, p. 238) lembra que "[...] o principal suporte legislativo pra a verificação do requisito da certeza no direito brasileiro se encontra nos arts. 402 e 403 do novo Código Civil."

Alguns acórdãos do Superior Tribunal de Justiça julgaram improcedentes casos clássicos de responsabilidade civil pela perda de uma chance com base no art. 1.059 do Código Civil, de 1916, hoje representado pelo art. 402 do Código Civil. (SILVA, 2013, p. 238)

Consta do Código Civil (BRASIL, Lei 10.406, 2002, arts. 402 e 403):

Art. 402. Salvo as exceções expressamente previstas em lei, as perdas e danos devidas ao credor abrangem, além do que ele efetivamente perdeu, o que razoavelmente deixou de lucrar.

Art. 403. Ainda que a inexecução resulte de dolo do devedor, as perdas e danos só incluem os prejuízos efetivos e os lucros cessantes por efeito dela direto e imediato, sem prejuízo do disposto na lei processual.

Apesar dos arts. 402 e 403 do Código Civil imporem rigoroso critério ao magistrado para reparar apenas danos efetivamente provados, a aceitação da teoria da perda de uma chance se encontra na nova maneira de considerar as possibilidades (SILVA, 2013, p. 238).

Judith Martins-Costa (2003, p. 362), ao comentar o art. 403, assevera que o teor do referido dispositivo legal, "afasta é o dano meramente hipotético, mas se a vítima provar a adequação do nexo causal entre a ação culposa e ilícita do lesante e o 
dano sofrido (a perda de probabilidade séria e real), configurados estarão os pressupostos do dever de indenizar".

A aceitação da teoria da responsabilidade civil pela perda de uma chance como uma espécie de dano certo aparece como orientação que o direito nacional segue e continuará a seguir, visto que, no ordenamento jurídico brasileiro não se encontra qualquer dispositivo que possa se tornar óbice para a aplicação da teoria da perda de uma chance. (SILVA, 2013, p. 239-240).

Portanto, verifica-se que não existe vedação legal que impossibilite a aplicação da teoria da perda de uma chance no ordenamento jurídico pátrio. Assim, amparada também pela doutrina, a jurisprudência tem caminho livre para sua aplicação prática nos tribunais.

Com efeito, em novembro de 2011, foi aprovado pela totalidade dos juristas presentes, o Enunciado 444 perante a $\mathrm{V}$ Jornada de Direito Civil, nos seguintes termos:

Enunciado 444. Art. 927: A responsabilidade civil pela perda de chance não se limita à categoria de danos extrapatrimoniais, pois, conforme as circunstâncias do caso concreto, a chance perdida pode apresentar também a natureza jurídica de dano patrimonial. A chance deve ser séria e real, não ficando adstrita a percentuais apriorísticos. (BRASIL, Enunciado 444. V Jornada de Direito Civil, 2012, p. 73).

Percebe-se, portanto, conforme ressaltado por Silva, que a aprovação do enunciado pela totalidade dos juristas demonstra a coesão doutrinária que já existe acerca da matéria. (SILVA, 2013, p. 219).

$\mathrm{Na}$ jurisprudência pátria, o Superior Tribunal de Justiça vem, recentemente, se dedicando à análise dos requisitos para aplicação da teoria, notadamente da seriedade da chance perdida. Em acórdão ao Recurso Especial n ${ }^{\circ}$. 1254141/PR, de lavra da Ministra Nancy Andrighi (BRASIL, Superior Tribunal de 
Justiça, 2012), restou analisada a possibilidade da aplicação da teoria da perda de uma chance na cura de uma paciente com câncer, visto que seu médico não utilizou os procedimentos indicados pelo Ministério da Saúde e pela literatura médica, diminuindo as chances de cura ou de a paciente ter uma sobrevida menos sofrida. Os autores sustentaram que a escolha equivocada de tratamento diminuiu a chance de cura da paciente ou de uma sobrevida menos sofrida, uma vez que, após o aparecimento de metástase, a paciente veio a óbito.

Neste acórdão, a Ministra verificou que restou comprovada a imperícia médica na escolha do tratamento, o que diminuiu as chances de cura da paciente. Assim, utilizando-se dos preceitos da teoria da perda de uma chance, entendeu que chance de cura perdida era indenizável.

Ademais, em outro acórdão da mesma Corte, ao Recurso Especial $n^{\circ}$. 1291247/RJ, de relatoria do Ministro Paulo de Tarso Sanseverino (BRASIL, Superior Tribunal de Justiça, 2014), a teoria da perda de uma chance foi aplicada em razão de que uma empresa foi contratada para colher células troncos de um recém-nascido. O momento oportuno para coleta é logo após o nascimento e realizada através do cordão umbilical. No caso julgado, a empresa ré não compareceu no momento do parto, perdendo a oportunidade da realização de um procedimento que poderá salvar a vida do autor (recém-nascido) caso venha a ter algumas doenças no futuro.

Todavia, em voto-vista vencido, a Ministra Nancy Andrighi entendeu por negar a aplicação da teoria da perda de uma chance ao caso, sustentando que não havia chance séria e real do autor adquirir uma patologia curável através das células tronco e ainda destacou a probabilidade de que no futuro haverá outros meios, que não o cordão umbilical, de se colher as células tronco. 
Verifica-se, portanto, que a análise efetuada pela Ministra coaduna-se com os estudos realizados nesta pesquisa. Não obstante isso, o seu voto restou vencido. Logo, contata-se que a jurisprudência pátria ainda encontra certa divergência acerca dos requisitos para aplicação da teoria da perda de uma chance, fazendo-o em hipóteses em que não houve comprovação de chance concreta e da probabilidade séria e real do evento danoso ocorrer.

\section{CONCLUSÃO}

Conforme proposto, este trabalho teve como objetivo analisar os critérios de aplicação e a utilização atual da teoria da perda de uma chance no ordenamento jurídico brasileiro.

Ao final, verificou-se que não há óbice legal para aplicação da teoria da perda de uma chance no direito brasileiro, uma vez que ela é compatível com a legislação de regência. A doutrina pátria, em sua grande maioria, recepcionou a teoria da responsabilidade civil pela perda de uma chance, recomendando a sua aplicação. A jurisprudência, por sua vez, apesar da resistência inicial, vem utilizando-a constantemente, conforme restou constatado.

Além disso, para a aplicação da teoria da perda de uma chance, mostra-se imprescindível a observância dos critérios analisados. Destaca-se o requisito da chance perdida ser séria e real. Com efeito, o estudo demonstrou que este critério para aplicação da teoria é alvo frequente de debates e divergências doutrinárias e jurisprudenciais.

No que tange à quantificação de indenização, constatou-se que ela deve ser proporcional ao percentual de chances da chance perdida a se concretizar.

Por fim, espera-se ter demonstrado a relevância da teoria 
da responsabilidade civil da perda de uma chance, bem como a sua conceituação, seus requisitos e a sua aceitação tanto pela doutrina quanto pela jurisprudência brasileira.

\section{REFERÊNCIAS}

BRASIL. Enunciado 444. V Jornada de Direito Civil. Organização Ministro Ruy Rosado de Aguiar Jr. Brasília: CJF, 2012.

Lei n. ${ }^{0}{ }^{10.406}$, de 10 de janeiro de 2002. Institui o Código Civil. Disponível em: <http:// www.planalto.gov.br/ccivil_03/leis/2002/L10406.htm>. Acesso em: 2 mar. 2016.

. Lei n. ${ }^{0}{ }^{13.105}$, de 16 de março de 2015. Código de Processo Civil. Disponível em: $<$ http:// www.planalto.gov.br/ccivil_03/_Ato2015-2018/2015/Lei/L13105.htm >. Acesso em: 2 mar. 2016.

Superior Tribunal de Justiça. Direito civil. Câncer. Tratamento inadequado. Redução das possibilidades de cura. Óbito. Imputação de culpa ao médico. Recurso Especial n. ${ }^{\circ}$ 1254141/PR, Relatora: Ministra Nancy Andrighi. 4 dez. 2012. Disponível em: $<$ http://www.stj.jus.br>. Acesso em: 2 mar. 2016.

. Superior Tribunal de Justiça. Recurso especial. Responsabilidade civil. Perda de uma chance. Descumprimento de contrato de coleta de células-tronco embrionárias do cordão umbilical do recém nascido. [...] Recurso Especial n. 1291247/RJ. Relator: Ministro Paulo de Tarso Sansverino. 19 ago. 2014. Disponível em: <http://www.stj.jus. br>. Acesso em: 2 mar. 2016.

CAVALIERI FILHO, Sergio. Programa de responsabilidade civil. 10. ed. rev. e ampl. São Paulo: Atlas, 2012.

DIAS, Sérgio Novais. Responsabilidade civil do advogado: na perda de uma chance. São Paulo: LTr, 1999.

KFOURI NETO, Miguel. Culpa médica e ônus da prova: presunções, perda de uma chance, cargas probatórias dinâmicas, inversão do ônus probatório e consentimento informado: responsabilidade civil em pediatria, responsabilidade civil em gineco-obstetrícia. São Paulo: Revista dos Tribunais, 2002.

, Miguel. Responsabilidade civil do médico. 5. ed. rev, atual. e ampl. São Paulo: Revista dos Tribunais, 2003.

MARTINS-COSTA, Judith. Comentários ao novo código civil: do inadimplemento das obrigações: (arts. 389 a 420). Rio de Janeiro: Forense, 2003.

MELLO, Fabiano de. A teoria da perda de uma chance. Revista Prática Jurídica, Brasília, ano X, n. 110, p. 6-8, maio. 2011.

NORONHA, Fernando. Direito das obrigações: fundamentos do direito das obrigações, introdução à responsabilidade civil. 2. ed. rev, e atual. São Paulo: Saraiva, 2007.

SAVI, Sérgio. Responsabilidade civil por perda de uma chance. São Paulo: Atlas, 2006.

SILVA, Rafael Peteffi da. Responsabilidade civil pela perda de uma chance: uma aná- 
lise do direito comparado e brasileiro. 3. ed. São Paulo: Atlas, 2013.

VENOSA, Ślvio de Salvo. Direito civil: responsabilidade civil. 12. ed. São Paulo: Atlas, 2012.

Artigo recebido em 31/05/2016

Artigo aprovado em 20/07/2016 